\title{
Caring for Aged Dementia Care Resident Study (CADRES) of person-centred care, dementia-care mapping, and usual care in dementia: a cluster-randomised trial

\author{
Lynn Chenoweth, Madeleine T King, Yun-Hee Jeon, Henry Brodaty, Jane Stein-Parbury, Richard Norman, Marion Haas, Georgina Luscombe
}

\section{Summary}

Background Evidence for improved outcomes for people with dementia through provision of person-centred care and dementia-care mapping is largely observational. We aimed to do a large, randomised comparison of person-centred care, dementia-care mapping, and usual care.

Methods In a cluster randomised controlled trial, urban residential sites were randomly assigned to person-centred care, dementia-care mapping, or usual care. Carers received training and support in either intervention or continued usual care. Treatment allocation was masked to assessors. The primary outcome was agitation measured with the Cohen-Mansfield agitation inventory (CMAI). Secondary outcomes included psychiatric symptoms including hallucinations, neuropsychological status, quality of life, falls, and cost of treatment. Outcome measures were assessed before and directly after 4 months of intervention, and at 4 months of follow-up. Hierarchical linear models were used to test treatment and time effects. Analysis was by intention to treat. This trial is registered with the Australia and New Zealand Clinical Trials Registry, number ACTRN12608000084381.

Findings 15 care sites with 289 residents were randomly assigned. Pairwise contrasts revealed that at follow-up, and relative to usual care, CMAI score was lower in sites providing mapping (mean difference 10 9, 95\% CI 0.7-21·1; $\mathrm{p}=0 \cdot 04)$ and person-centred care $(13 \cdot 6,3 \cdot 3-23 \cdot 9 ; \mathrm{p}=0 \cdot 01)$. Compared with usual care, fewer falls were recorded in sites that used mapping $(0.24,0.08-0.40 ; \mathrm{p}=0.02)$ but there were more falls with person-centred care $(0 \cdot 15$, $0 \cdot 02-0 \cdot 28 ; \mathrm{p}=0 \cdot 03)$. There were no other significant effects.

Interpretation Person-centred care and dementia-care mapping both seem to reduce agitation in people with dementia in residential care.

Funding Australian Health Ministers' Advisory Council.

\section{Introduction}

Progressive deterioration in cognition, function, and behaviour make people with dementia increasingly dependent on others for normal activities of daily living. The complex needs of people with dementia can be difficult to meet, leading to need-driven dementiacompromised behaviours-also called behavioural and psychological symptoms of dementia or unmet need behaviours. ${ }^{1}$ Such behaviours include sleep-wake cycle disturbance, screaming, crying, repeated calling out, and pacing. These behaviours are difficult for family members to manage and can lead to carer distress and placement of people in residential care. ${ }^{2}$

Dementia prevalence is likely to quadruple worldwide by 2041, necessitating changes in care policy and healthcare systems. ${ }^{3}$ The growing prevalence of dementia in Australia has affected residential-care accreditation, and although care standards are improving, alarming instances of poor care persist. ${ }^{4}$ One important issue for providers of residential care is how to maintain acceptable standards of care and quality of life in dementia with limited funds and staff, inadequate training of care staff, and increasing comorbidity and dependency levels in dementia. ${ }^{5}$
In residential care, practices of physical restraint or neglect of psychosocial needs can exacerbate need-driven dementia-compromised behaviours, leading to loss of self-care, decision making, and social engagement and increased social alienation, ${ }^{6}$ comprising what Kitwood called malignant social psychology. Very harmful effects of malignant social psychology in care can be deeply damaging to people's sense of personhood (ie, the recognition, respect, and trust bestowed upon one human being by others in social relationships) and might even undermine physical wellbeing. For example, dehumanising acts by care staff such as labelling, disempowerment, objectification, and infantilisation affect many people in care. ${ }^{1,4}$ The traditional focus of nursing on physical features of activities of daily living has been derived from the biomedical model of acute care, and the resulting neglect of psychosocial needs means that many people with dementia spend long hours alone and emotionally distressed in residential care. ${ }^{6}$ Kitwood $^{1}$ showed that malignant social psychology results from the biomedical focus in care and not necessarily because of malignant intent of carers. Because of the complexity of dementia, integrated care approaches are needed to maintain wellbeing and quality
Lancet Neurol 2009; 8: 317-25

Published Online March 12, 2009 DOI:10.1016/S14744422(09)70045-6

See Reflection and Reaction page 302

Faculty of Nursing, Midwifery and Health (LChenoweth PhD, Y-H Jeon PhD,

J Stein-Parbury PhD) and Centre for Health Economics Research and Evaluation (R Norman MSc, $M$ Haas PhD), University of Technology Sydney, NSW, Australia; Health and Ageing Research Unit, South Eastern Sydney-Illawarra Area Health Service, Sydney, NSW, Australia (L Chenoweth); Psychooncology Co-operative Research Group (PoCoG), School of Psychology (MT King PhD) and Faculty of Medicine (G Luscombe PhD), University of Sydney, NSW, Australia; Australian Primary Health Care Research Institute, Australian National University, Australian Capital Territory, Australia (Y-H Jeon PhD); Dementia Collaborative Research Centre, School of Psychiatry, University of New South Wales, and Academic Department for Old Age Psychiatry, Prince of Wales Hospital, Sydney, NSW, Australia (H Brodaty DSc); and Mental Health Nursing Professorial Unit, South Eastern Sydney-Illawarra Area Health Service, Sydney, NSW, Australia (J Stein-Parbury)

Correspondence to: Lynn Chenoweth, Faculty of Nursing, Midwifery and Health, University of Technology Sydney, PO Box 222 Lindfield, NSW 2070, Australia lynnette.chenoweth@uts. edu.au 
of life and to reduce the incidence of need-driven dementia-compromised behaviours. ${ }^{6}$

Person-centred care is a holistic alternative to conventional care practices ${ }^{7,8}$ that can moderate the effects of malignant social psychology ${ }^{1}$ and help personhood to persist as dementia develops. Care that addresses residents' total human needs can mitigate cognitive and functional deterioration. Personhood is a product of relationships with others ${ }^{1}$ and can be nurtured or diminished, depending on whether the person is being valued or depersonalised in care. ${ }^{6}$ Use of person-centred care, which can be learned by use of education and staff support, is becoming more common in residential care, because itcan reduce need-driven dementia-compromised behaviours and help maintain personhood.' CohenMansfield and colleagues ${ }^{10}$ reported a reduction in agitation in residents of nursing homes through care techniques personalised on the basis of individuals' preferences and needs. Sloane and co-workers ${ }^{11}$ confirmed reduced resident anxiety and agitation by incorporating person-centred care in staff training for specific bathing practices. Fossey and colleagues ${ }^{12}$ also showed the effectiveness of this practice in reducing the use of neuroleptics in management of behavioural symptoms of residents with dementia in a cluster-randomised trial. Nevertheless, few trials have shown effectiveness of person-centred care in reducing need-driven dementiacompromised behaviours and improving quality of life, ${ }^{9}$ and none has included an economic assessment.

Dementia-care mapping is a method of implementing person-centred care underpinned by the socialpsychological theory of personhood in dementia. ${ }^{13}$ Systematic observation of factors associated with expressions of wellbeing in people with dementia help staff to think about the degree to which the care they provide is person-centred. Detailed observations and scoring of the residents' wellbeing are fed back to care staff and their managers to help planning, implementation, and assessment of person-centred care. Evidence for the effectiveness of dementia-care mapping is mainly descriptive and observational. ${ }^{14,15}$ Because mapping requires expert training and is labour-intensive and costly, research into its effectiveness is warranted..$^{16,17}$ Whether person-centred care is beneficial and whether dementia-care mapping is the best way of implementing such care in clinical practice are unknown.

The Caring for Aged Dementia Care Resident Study (CADRES) was done to investigate the effectiveness of person-centred care and dementia-care mapping compared with each other and with conventional dementia care and to examine whether either intervention can decrease need-driven dementia-compromised behaviours. The study also aimed to assess whether, relative to usual care, these interventions could improve quality of life and reduce the use of psychotropic drugs or restraints and rates of accidents or injuries. We also estimated the cost of each treatment strategy.

\section{Methods}

\section{Sites and participants}

15 of 30 residential care sites screened across metropolitan Sydney (Australia) in the therapeutic environment screening survey for nursing homes (TESS-NH) ${ }^{18}$ were selected for this study because they have task-focused not person-centred, care systems. The 15 sites were also selected because they had similar management structure, staffing, standards, and size. Study participation was approved by the University of Technology Sydney Human Research Ethics Committee and by care-service approval committees at each of the 15 centres. From a potential 682 people in the 15 sites, 324 eligible residents were selected by facility managers or directors before randomisation of sites. Residents fulfilled the criterion that persistent need-driven behaviours made it difficult for staff to provide them with quality care. ${ }^{19}$ We used a mixed experimental design to aid comparability of the sites allocated to the three interventions; because the intervention was based on models of care, we randomised at the site level. Allocation was done by the study statistician (MTK), who was unaware of the identity of sites, using an $\mathrm{SAS}^{20}$ program. Three sites were large care services with two separate dementia-care units with separate management and staff. These sites were assigned to treatment according to a balanced incomplete-block design with the two units at each site treated as separate sites for randomisation: site one (person-centred care, dementia-care mapping), site two (dementia-care mapping, usual care), and site three (person-centred care, usual care). The remaining sites formed a randomised complete-block design, with allocation to each group.

We calculated the number of residents needed to detect a medium treatment effect size with $90 \%$ power with a randomised complete-block design. This number was adjusted to account for within-site correlation of $0 \cdot 07$, estimated from a pilot study in a similar population, ${ }^{21}$ and to allow for a $20 \%$ drop-out rate from baseline to followup, to give a recruitment target of 300 residents (20 per site) and a final sample of 240 (16 per site). Residents were eligible if they had a medical diagnosis of dementia and were older than 60 years of age; had Australian resident classification scale $(\mathrm{RCS})^{19}$ categories 1-3 (high dependency), low cognitive function (levels C or D on question 8 of the RCS), and need-driven dementiacompromised behaviours (questions 9-16); had written informed consent given on their behalf by their guardian or had given verbal assent themselves; and were in permanent placement. Exclusion criteria included lack of consent, serious comorbidities complicating or masking dementia, palliative care, unremitting pain and distressing physical symptoms, and respite placement.

\section{Procedures}

Researchers implemented person-centred care (JS-P) and dementia-care mapping (LC and Y-HJ). These three authors were trained by people accredited by Bradford 
University (Bradford, UK), were supervised and assessed for competence at unrelated sites during the pilot study, had participated in hundreds of hours of both intervention procedures in ten care homes for the elderly before this study, and used Bradford University's learning resources and protocols for staff training and support.

JS-P led 2-day training sessions in person-centred care for two care staff selected by managers as competent and interested from each of the five sites. Bradford University's training manual ${ }^{8}$ was used as a resource during and after the sessions. Topics covered included understanding that behaviour is a form of communication, recognising that feelings persist despite cognitive impairment, acknowledging feelings during social interactions, and focusing on the unique way that residents express feelings and needs to change usual care. The training sessions explored how staff actions contribute to behaviours of residents that result from dementia. Training challenged previously held beliefs by emphasising that social interactions, especially those that engage residents on an affective level, help to preserve personhood and build meaningful relationships. JS-P assisted the trained staff to develop and implement care practices based in person-centred care for 28 of the 98 participating residents from the five sites. Central to these practices was a careful review of residents' life histories. JS-P visited each site twice to help staff change practices to include person-centred care for all 98 residents. JS-P also supported staff via regular telephone contact during the 4 month intervention period to assess the planned changes to practice and care approaches as needed.

LC and Y-HJ did dementia-care mapping at the five sites after their inter-rater reliability for scoring had been established (concordance coefficient $0 \cdot 86$ ). Two care staff at each site who were trained by a Bradford-trained expert did mapping with LC and Y-HJ for $6 \mathrm{~h}$ per day for 2 days (before, during, and after breakfast and lunch times and during recreational activity time in the afternoon), to identify factors related to resident wellbeing. Observations included positive and negative care delivery, namely positive events and personal detractions, and wellbeing scores within the 24 behavioural categories defined in dementia-care mapping. ${ }^{22}$ LC's and Y-HJ's observation data were reported to nurses within $24 \mathrm{~h}$ of mapping and included composite wellbeing scores for individual residents, associations between care practices and staff-resident interactions (positive events and personal detractions), and wellbeing expressions present in needdriven dementia-compromised behaviours. LC and Y-HJ conferred with the trained staff to develop individual care plans for residents by considering the individuals' histories, needs, and preferences. Trained staff subsequently helped their colleagues to implement person-centred care plans over the 4-month intervention period, with regular telephone support from LC and Y-HJ.
Supported by the results of the TESS-NH baseline site screen, ${ }^{18}$ and typical of Australian residential care for elderly people and people with dementia, ${ }^{4,5}$ usual care continued uninterrupted at the five control sites. Usual care was characterised by custodial and physical taskoriented practices, including unwarranted use of physical restraint, a tendency to neglect residents' psychosocial needs when meeting activities of daily living, with little attention being paid to promotion of resident choice and encouragement of self-determination.

We recorded demographic and clinical information. Severity of dementia and impairment was recorded with two scales: the global deterioration rating scale for assessment of primary degenerative dementia, ${ }^{23}$ which measures severity of dementia (range stage 1-7) with high scores associated with severe dementia; and the Australian resident classification scale, ${ }^{19}$ which measures levels of dependency with a range from 1 (highest care need) to 8 (self-caring).

We recorded quality of care with the following scores: the special care unit environmental quality scale within TESS$\mathrm{NH}{ }^{18}$ which measures cleanliness, familiarity, lighting, maintenance, noise, safety, and stimulation in nursing homes, with good environments receiving high scores; and the quality interactions schedule (QUIS), ${ }^{24}$ which measures quality interactions between care staff and residents, and care quality, through $6 \mathrm{~h}$ of observation per site (three $2 \mathrm{~h}$ periods, matching observation periods for dementia-care mapping). We counted the frequencies of five categories of interactions: positive care, positive social, neutral, negative protective, and negative restrictive.

Outcome measures were assessed before the intervention and directly after the 4 months of intervention, and then at 4 months' follow-up. We recorded need-driven dementia-compromised agitation with the 29-item CohenMansfield agitation inventory (CMAI), ${ }^{25}$ which measures the frequency (from never, 1, to several times an hour, 7) of agitation during the past 2 weeks (range 29-203), with high scores relating to agitation. The CMAI was chosen a priori as the primary outcome measure because it was expected to be more responsive than other measures to the effects of the psychosocial care interventions tested in this study (because it includes 29 discrete and readily observable behaviours of agitation such as pushing, biting, scratching, hiding things, and hoarding things). We recorded psychological and psychiatric behaviours occurring in dementia with the neuropsychiatric inventory for the nursing home ${ }^{26}$ which measures frequency and severity of 12 domains of severe symptoms (delusions, hallucinations, agitation or aggression, depression or dysphoria, anxiety, elation or euphoria, apathy or indifference, disinhibition, irritability or lability, aberrant motor behaviour, sleep, and appetite and eating disorders) occurring per day during one week (range for each domain from 0 to 12), for which higher scores indicate worse behaviour. Quality of life in late-stage dementia (QUALID) ${ }^{27}$ recorded 11 observable behaviours in affective 


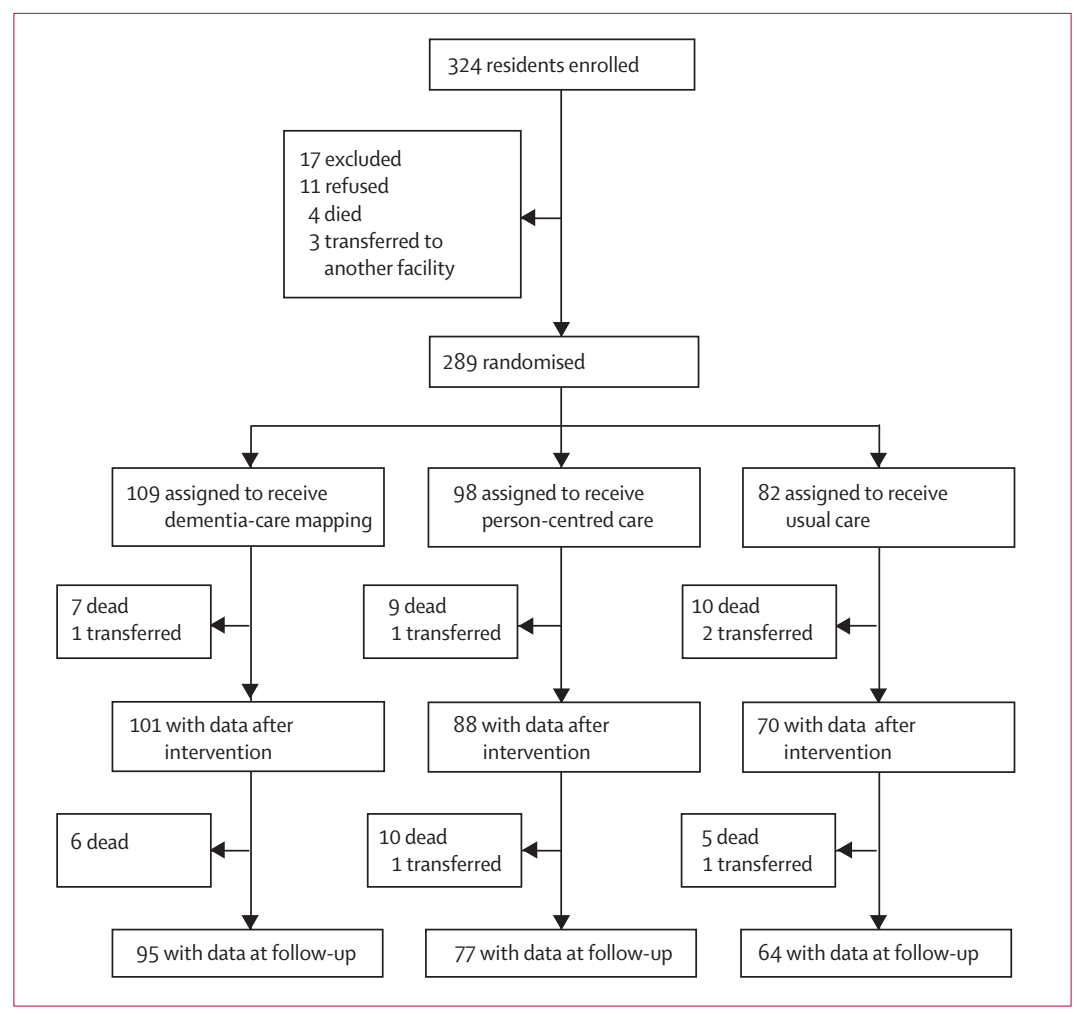

Figure 1: Trial profile signed agreement with staff and managers not to mention the intervention, by ensuring that questionnaires included no intervention information, and by regularly checking with the research assistants that they remained unaware of treatment allocation throughout the study. These three assistants collected data on quality of care practice and use of physical restraints through direct QUIS observations. Data for CMAI, neuropsychiatric inventory for the nursing home, QUALID, and global deterioration rating scale for assessment of primary degenerative dementia were obtained through observation and interviews with the nurses and direct care staff who were judged to be most knowledgeable of individual residents' disorders and who regularly cared for them. Interviews were done with individuals and small groups of staff, and scores were derived through consensus. The three research assistants interviewed the same staff from each site at all three stages of data collection to achieve the best reliability of outcome measure scoring. The repeated measures design and analysis ensured that any systematic difference due to allocation of research assistants to intervention groups was adjusted for in the statistical analysis of the main study hypotheses. Demographics, basic clinical information, and information on incidents and use of drugs were obtained from clinical charts and official site records with support from managers and quality assurance personnel.

A detailed report of the economic analysis is available. ${ }^{29}$ We calculated the incremental cost-effectiveness ratio, which is the cost of a one-point improvement in outcome measure; in this case the CMAI. Cost components were measured over the 4 months of intervention. Personnel costs included the time used by the trainer to educate and support staff in each site, the expected time staff spent on activities specific to intervention, and the replacement costs of backfilling positions while staff received training. Data on use of psychotropic drugs were coded according to the Australian pharmaceutical benefits scheme ${ }^{30}$ to estimate the mean cost per drug per resident per week. Because data collection identified the drug not the brand name, we assumed that all drugs were generic: cost data correct as of 2008. Capital costs were not included because neither dementia-care mapping nor person-centred care would incur the use of any additional capital beyond that used in usual care. At time of publication AUS $\$ 1 \cdot 00=\mathrm{US} \$ 0 \cdot 65$.

\section{Statistical analysis}

Differences between the intervention groups in characteristics of residents and sites at baseline were tested with $\chi^{2}$ tests for categorical variables, KruksalWallis tests for continuous variables with skewed distributions, and one-way ANOVA for the only normally distributed continuous variable (residentclassification scale total score). The study hypotheses were tested with general linear models, following the methods for analysis of nested cohort designs described by Murray. ${ }^{30}$ We used two complementary modelling 
approaches. For the primary analysis, all three time points were included as outcomes to test for global group differences and for trends over time during the study period. As a secondary analysis, the baseline outcome was included as a covariate for the remaining two time points to give the best precision of pairwise contrasts of treatment groups at end-of-treatment and follow-up assessments. In both modelling approaches, characteristics of site and residents that were possible confounding variables were included as covariates. The aim was to achieve the most accurate and precise estimates of the treatment effect. With methods described by Murray, ${ }^{31}$ covariates were retained if there was evidence of confounding (ie, if estimates of treatment effect differed substantially in the adjusted versus unadjusted models), if they explained significant variation in the outcome, and if they improved the precision of the estimates of treatment effect.

Hierarchical linear models were estimated for the continuous outcome variables (CMAI, neuropsychiatric inventory, and QUALID) with SAS Proc Mixed, ${ }^{20}$ and hierarchical logistic models were estimated for the dichotomised medication variables, with SAS Proc Glimmix, ${ }^{32}$ with the SAS code provided by Murray. ${ }^{31}$

For the economic assessment, the mean change in CMAI score per treatment group was multiplied by the average number of residents in that treatment group to give aggregate agitation averted or caused. The incremental cost-effectiveness ratio was calculated by dividing the cost of each intervention by this aggregate. Thus, the result of the economic assessment was a cost per CMAI point averted. Because several cost variables were estimated under uncertainty, a univariate sensitivity analysis assessed the responsiveness of the conclusions to the assumptions made in the economic assessment, enabling the robustness of the results to be gauged. The variables included were the cost of staff time, the amount of support received by a unit after the intervention, and the time commitment needed to complete mapping throughout the trial period. This trial is registered with the Australia and New Zealand Clinical Trials Registry, number ACTRN12608000084381.

\section{Role of the funding source}

The funding source had no role in study design, data collection, data analysis, or writing of the report. The corresponding author and all coauthors had full access to the study data and had final responsibility for the decision to submit for publication

\section{Results}

Across 15 sites, 324 residents were enrolled; 17 were excluded (five did not have dementia, five did not meet age criteria, and seven did not meet criteria on the resident classification scale), and 11 did not want to participate. Of the remaining 296 eligible residents, 289 (97\%) participated in the study (figure 1). All 15 sites and 236 of 289 (82\%) of recruited residents remained in the study to completion. Compared with residents who did not complete the study, those who did had similar CMAI $(\mathrm{p}=0 \cdot 48)$ and neuropsychiatric inventory scores $(\mathrm{p}=0.56)$ but, unexpectedly, lower QUALID scores $(\mathrm{p}=0 \cdot 01)$.

Table 1 shows baseline characteristics of sites and residents. Intervention groups differed at the site level in terms of safety (sites providing person-centred care were less safe) and two of the QUIS domains (staff at sites providing person-centred care had more positive social and care interactions). These differences were judged by study clinicians to be potential confounders. As these last two variables were highly correlated $(\mathrm{r}=0 \cdot 70)$, only one (positive social interactions) was used as a covariate in

\begin{tabular}{|c|c|c|c|}
\hline & $\begin{array}{l}\text { Dementia- } \\
\text { care mapping }\end{array}$ & $\begin{array}{l}\text { Person-centred } \\
\text { care }\end{array}$ & Usual care \\
\hline \multicolumn{4}{|l|}{ Sites } \\
\hline Number & 5 & 5 & 5 \\
\hline Number of beds & $52(14 \cdot 4)$ & $47(18.9)$ & $53(23.0)$ \\
\hline $\begin{array}{l}\text { Number of residents per } \\
\text { staff }\end{array}$ & $0.73(0.18)$ & $0.92(0.57)$ & $0 \cdot 86(0 \cdot 36)$ \\
\hline \multicolumn{4}{|l|}{ Quality of interactions* } \\
\hline Positive care & $1.6(0.44)$ & $3 \cdot 3(1 \cdot 3)$ & $1 \cdot 6(1 \cdot 1)$ \\
\hline Positive social & $0.72(0.23)$ & $4 \cdot 5(1 \cdot 6)$ & $0.83(0.55)$ \\
\hline \multicolumn{4}{|l|}{ Environment } \\
\hline Cleanliness & $10 \cdot 4(1 \cdot 3)$ & $10 \cdot 2(1 \cdot 8)$ & $11 \cdot 2(1 \cdot 1)$ \\
\hline Familiarity & $8.0(3.3)$ & $9 \cdot 0(3 \cdot 1)$ & $6 \cdot 2(3 \cdot 3)$ \\
\hline Lighting & $11 \cdot 2(1 \cdot 3)$ & $11.0(1 \cdot 2)$ & $10 \cdot 6(1 \cdot 7)$ \\
\hline Maintenance & $6 \cdot 2(1 \cdot 8)$ & $5 \cdot 4(1 \cdot 7)$ & $7 \cdot 0(1 \cdot 7)$ \\
\hline Noise & $10 \cdot 0(1 \cdot 9)$ & $11 \cdot 2(1 \cdot 8)$ & $10 \cdot 2(1 \cdot 6)$ \\
\hline Safety & $9.6(0.55)$ & $8.0(1.6)$ & $9.8(0.45)$ \\
\hline Stimulation & $8 \cdot 6(1 \cdot 1)$ & $9 \cdot 4(0.89)$ & $8 \cdot 4(1 \cdot 8)$ \\
\hline \multicolumn{4}{|l|}{ Residents } \\
\hline Number & 109 & 98 & 82 \\
\hline Age (years) & $83(7 \cdot 6)$ & $84(6 \cdot 4)$ & $85(6 \cdot 6)$ \\
\hline Women (\%) & $90(83 \%)$ & $74(76 \%)$ & $60(73 \%)$ \\
\hline Born in Australia (\%) & $80(73 \%)$ & $74(76 \%)$ & $46(58 \%) \dagger$ \\
\hline English speakers (\%)‡ & $102(94 \%)$ & $87(89 \%)$ & $74(90 \%)$ \\
\hline \multicolumn{4}{|c|}{ Resident classification scale category } \\
\hline 1 (highest care needs) & $25(23 \%)$ & $50(51 \%)$ & $17(21 \%)$ \\
\hline 2 & $69(63 \%)$ & $43(44 \%)$ & $50(61 \%)$ \\
\hline 3 (lowest care needs) & $15(14 \%)$ & $5(5 \%)$ & $15(18 \%)$ \\
\hline $\begin{array}{l}\text { Resident classification } \\
\text { scale total score }\end{array}$ & $76.0(7 \cdot 0)$ & $81 \cdot 5(8 \cdot 2)$ & $75 \cdot 8(8 \cdot 0)$ \\
\hline $\begin{array}{l}\text { Global deterioration } \\
\text { scale }\end{array}$ & $5 \cdot 6(1 \cdot 3)$ & $5.6(0.73)$ & $5 \cdot 3(1 \cdot 1)$ \\
\hline Comorbid diseases & $2.2(0.94)$ & $2 \cdot 0(1 \cdot 1)$ & $2.4(0.86)$ \\
\hline \multicolumn{4}{|c|}{$\begin{array}{l}\text { Data are number, mean (SD), or number (\%). Quality of interactions (QUIS) scores } \\
\text { were measured for staff members; site-level averages were entered as covariates in } \\
\text { the generalised linear models. Environment was assessed with TESS-NH domains at } \\
\text { the site level. A higher total score on the resident classification scale means that a } \\
\text { greater degree of care is needed. *In other QUIS domains, numbers of negative } \\
\text { interactions were too low to do statistical analyses. †Data from } 80 \text { residents; data } \\
\text { missing for two. \#English speakers at home. }\end{array}$} \\
\hline
\end{tabular}




\begin{tabular}{|c|c|c|c|}
\hline & $\begin{array}{l}\text { Before } \\
\text { intervention } \\
(n=289)\end{array}$ & $\begin{array}{l}\text { After } \\
\text { intervention } \\
(n=259)\end{array}$ & $\begin{array}{l}\text { Follow-up } \\
(n=236)\end{array}$ \\
\hline \multicolumn{4}{|c|}{ Agitation $(\mathrm{CMAI}): \mathrm{p}_{\mathrm{G}}=0.33, \mathrm{p}_{\mathrm{T}}=0.47, \mathrm{p}_{\mathrm{GT}}=0.005$} \\
\hline DCM & $46 \cdot 1(6 \cdot 5)$ & $45 \cdot 1(6 \cdot 6)$ & $43 \cdot 7(6 \cdot 5)^{*}$ \\
\hline PCC & $47 \cdot 5(9 \cdot 1)$ & $41 \cdot 7(9 \cdot 2)$ & $37 \cdot 2(9 \cdot 1) \dagger$ \\
\hline Usual care & $50 \cdot 3(6 \cdot 8)$ & $58 \cdot 7(6 \cdot 9)$ & $57 \cdot 7(6 \cdot 8)$ \\
\hline \multicolumn{4}{|c|}{ Neuropsychiatric inventory: $\mathrm{p}_{\mathrm{G}}=0.68, \mathrm{p}_{\mathrm{T}}=0.05, \mathrm{p}_{\mathrm{GT}}=0.30$} \\
\hline DCM & $12 \cdot 7(5 \cdot 1)$ & $16 \cdot 8(5 \cdot 1)$ & $13 \cdot 5(5 \cdot 1)$ \\
\hline PCC & $21 \cdot 3(6 \cdot 8)$ & $14 \cdot 5(6 \cdot 9)$ & $12 \cdot 6(6 \cdot 9)$ \\
\hline Usual care & $16 \cdot 9(5 \cdot 3)$ & $20 \cdot 2(5 \cdot 4)$ & $15 \cdot 3(5 \cdot 3)$ \\
\hline \multicolumn{4}{|c|}{ QUALID: $\mathrm{p}_{\mathrm{G}}=0.78, \mathrm{p}_{\mathrm{T}}=0.80, \mathrm{p}_{\mathrm{GT}}=0.33$} \\
\hline DCM & $23 \cdot 5(1.6)$ & $23.4(1.6)$ & $24.5(1.6)$ \\
\hline PCC & $22 \cdot 7(2 \cdot 2)$ & $21 \cdot 5(2 \cdot 2)$ & $20 \cdot 8(2 \cdot 2)$ \\
\hline Usual care & $23 \cdot 2(1 \cdot 7)$ & $23 \cdot 7(1 \cdot 7)$ & $24 \cdot 4(1 \cdot 7)$ \\
\hline \multicolumn{4}{|c|}{ 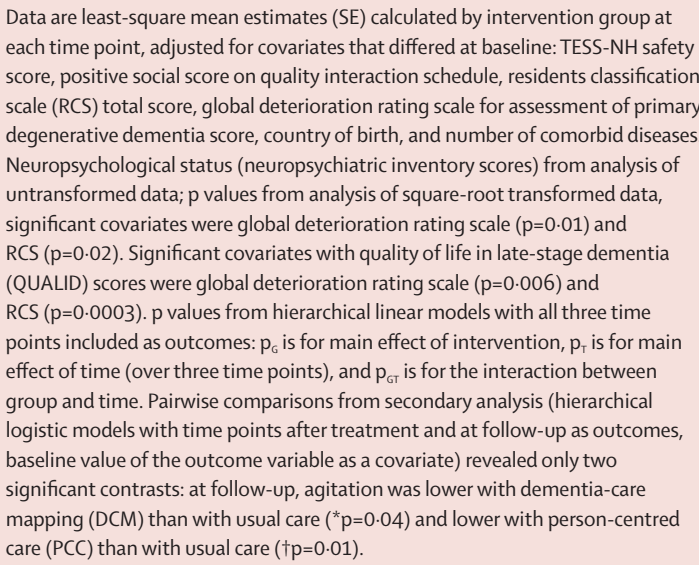 } \\
\hline
\end{tabular}

the outcome models. In all other domains of QUIS, the numbers of negative interactions and care practices, such as restraint use, were so low that statistical tests could not be done. Four characteristics of residents differed substantially among the intervention groups at baseline: person-centred care sites had a higher proportion of residents with RCS category 1 (greater care needs); fewer residents in usual care sites were born in Australia; residents at usual care sites had less severe dementia; and the number of comorbid diseases was highest among residents receiving usual care and lowest among those receiving person-centred care. These differences were all potential confounders. Six covariates were entered in the outcome models to adjust for these baseline differences.

Table 2 shows results from primary analysis of three of the resident outcome measures. Evidence suggests confounding in this model, so we present the adjusted estimates (table 2). For the primary outcome, agitation as measured by the CMAI, the group by time interaction was significant. Agitation increased in the usual care sites during the study period and persisted at follow-up $(\mathrm{p}=0 \cdot 03$ for time trend within usual care; figure 2), whereas it decreased with person-centred care during the study

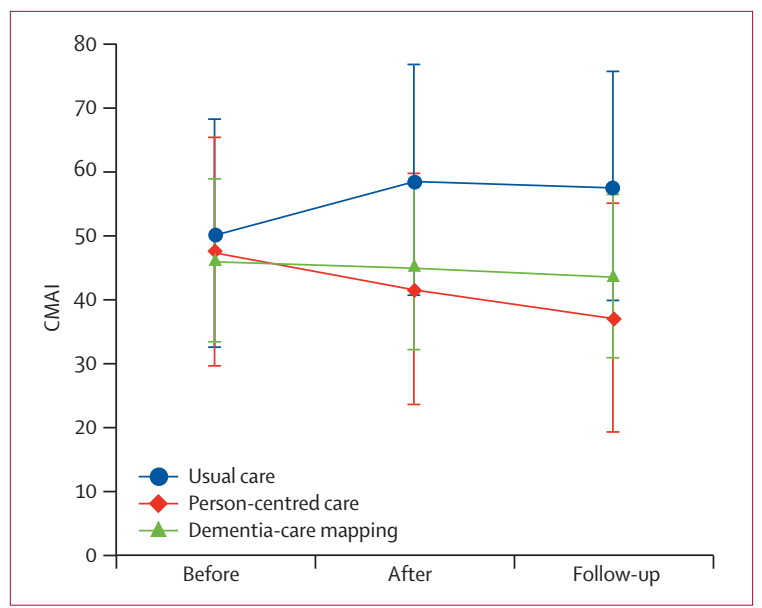

Figure 2: Agitation adjusted for covariates that differed at baseline Adjusted mean CMAI scores ( $95 \% \mathrm{Cl}$ ) by intervention group.

period with a further drop at follow-up $(\mathrm{p}=0.01$ for time trend). The small reduction in agitation in sites that provided dementia-care mapping was not statistically significant ( $\mathrm{p}=0 \cdot 77$ for time trend). Secondary analyses of CMAI scores, after adjusting for baseline CMAI score, showed no evidence of confounding due to the other covariates. Futhermore, no analyses explained additional variance in the model, and inclusion of these covariates did not improve precision of the estimates of treatment effect. Therefore the following results are based on a model adjusted only for baseline CMAI. At follow-up, and relative to the usual care sites, agitation of residents was significantly lower in the sites providing dementia-care mapping (mean CMAI difference 10.9 points, $95 \%$ CI $0 \cdot 7-21 \cdot 1 ; \quad \mathrm{p}=0.04)$ and person-centred care $(13 \cdot 6$, $3 \cdot 3-23 \cdot 9 ; \mathrm{p}=0 \cdot 01)$. None of the other pairwise contrasts of treatment groups was statistically significant.

For the measure of the psychiatric symptoms of dementia, the neuropsychiatric inventory, there was a significant overall time effect (table $2, \mathrm{p}=0 \cdot 05$ ), which was driven by the sites providing person-centred care, in which there was a significant trend over time $(\mathrm{p}=0 \cdot 04)$. There were no other statistically significant results for neuropsychiatric inventory or quality of life as measured by QUALID.

The secondary hypotheses that person-centred care and dementia-care mapping would lower intake of psychotropic drugs and rate of accidents or injuries, relative to usual care, were not supported (table 3). The numbers of admissions to hospital subsequent to accidents or injuries were so low that statistical tests were not done. The only statistically significant group effect was for antipsychoticdrug doses, which were higher in person-centred care sites than in either dementia-care mapping or usual care sites at baseline and this difference lasted until follow-up. A significant effect of intervention was detected at followup for the number of falls. The proportion of residents experiencing falls (table 3) decreased from baseline to 
follow-up with dementia-care mapping, whereas it increased with person-centred and usual care. The mean difference between dementia-care mapping and usual care in change in proportion of residents with falls from baseline to follow-up was 0.24 (95\% CI $0 \cdot 08-0 \cdot 40$ ), whereas the difference between person-centred care and usual care was $0 \cdot 15(0 \cdot 02-0 \cdot 28)$. The statistical significance of these differences were apparent in the pairwise comparisons from the secondary analyses; after adjusting for baseline differences in the proportion of falls and other baseline covariates, at follow-up there were fewer falls with dementia-care mapping than in usual care $(p=0.02)$ and more falls in person-centred care than in usual care $(p=0 \cdot 03)$. No other differences were statistically significant.

Drug cost did not differ between any treatment at any time point ${ }^{32}$ and was excluded from the analysis. The cost per site of dementia-care mapping was AUS\$10034. The largest component of cost of dementia-care mapping was the time spent mapping. The cost per site of personcentred care was $\$ 2250$. We calculated the cost per CMAI score change (table 4). The cost per behaviour averted relative to usual care was higher for dementia-care mapping than for person-centred care, both at the end of intervention and at follow-up. In the univariate sensitivity analysis, reported in full elsewhere. ${ }^{29}$ The cost per CMAI point averted for person-centred care relative to usual care was \$6.23-9.79 immediately after intervention and $\$ 5 \cdot 00-7 \cdot 86$ at follow-up.

\section{Discussion}

Agitation, a major symptom of distress and need-driven dementia-compromised behaviours, was lower with both person-centred care and dementia-care mapping than with usual care, confirming previous research. ${ }^{10,11,20}$ Our results confirm the conclusion made in a comprehensive review of non-pharmacological interventions for the management of need-driven dementiacompromised behaviours ${ }^{33}$ that the most promising treatments seem to be individually tailored behavioural interventions. The implementation costs of personcentred care are lower than for dementia-care mapping, which requires more intensive training. We believe that the results of this study are generalisable to different centres and health systems.

\begin{tabular}{|c|c|c|c|}
\hline & $\begin{array}{l}\text { Before } \\
\text { intervention } \\
(n=289)\end{array}$ & $\begin{array}{l}\text { After } \\
\text { intervention } \\
(n=259)\end{array}$ & $\begin{array}{l}\text { Follow-up } \\
(n=236)\end{array}$ \\
\hline \multicolumn{4}{|c|}{ Incidents: $\mathrm{p}_{\mathrm{G}}=0.15, \mathrm{p}_{\mathrm{T}}=0.06, \mathrm{p}_{\mathrm{GT}}=0.89$} \\
\hline DCM & $0 \cdot 40 \%$ & $0 \cdot 49 \%$ & $0 \cdot 46 \%$ \\
\hline PCC & $0.43 \%$ & $0.53 \%$ & $0.44 \%$ \\
\hline Usual care & $0 \cdot 25 \%$ & $0 \cdot 37 \%$ & $0 \cdot 37 \%$ \\
\hline \multicolumn{4}{|c|}{ Falls: $p_{G}=0.79, p_{T}=0.26, p_{G}=0.13$} \\
\hline DCM & $0 \cdot 27 \%$ & $0 \cdot 24 \%$ & $0 \cdot 20 \% *$ \\
\hline PCC & $0 \cdot 32 \%$ & $0 \cdot 37 \%$ & $0.34 \% \dagger$ \\
\hline Usual care & $0 \cdot 13 \%$ & $0.27 \%$ & $0 \cdot 30 \%$ \\
\hline \multicolumn{4}{|c|}{ Antipsychotic-drug doses: $p_{G}=0.01, p_{T}=0.66, p_{G T}=0.66$} \\
\hline DCM & $0 \cdot 15 \%$ & $0 \cdot 19 \%$ & $0 \cdot 15 \%$ \\
\hline PCC & $0.42 \%$ & $0 \cdot 30 \%$ & $0 \cdot 34 \%$ \\
\hline Usual care & $0.19 \%$ & $0 \cdot 14 \%$ & $0 \cdot 14 \%$ \\
\hline \multicolumn{4}{|c|}{ Benzodiazepine-drug doses: $\mathrm{p}_{\mathrm{G}}=0.40, \mathrm{p}_{\mathrm{T}}=0.88, \mathrm{p}_{\mathrm{GT}}=0.98$} \\
\hline DCM & $0 \cdot 21 \%$ & $0 \cdot 20 \%$ & $0 \cdot 17 \%$ \\
\hline PCC & $0.07 \%$ & $0.06 \%$ & $0.07 \%$ \\
\hline Usual care & $0 \cdot 25 \%$ & $0.23 \%$ & $0 \cdot 23 \%$ \\
\hline \multicolumn{4}{|c|}{$\begin{array}{l}\text { Proportions are adjusted for covariates. The only outcome with statistically } \\
\text { significant covariates was chlorpromazine: positive social scale on the quality } \\
\text { interactions schedule (QUIS; } \mathrm{p}=0.048 \text { ) and TESS-NH safety score ( } \mathrm{p}=0.03 \text { ). } \\
\text { Incidents include falls, injuries (eg, fractures, lacerations, bruises), drug errors, and } \\
\text { behavioural events (eg, physical aggression, falls). Antipsychotic and } \\
\text { benzodiazepine doses were converted into chlorpromazine and diazepam } \\
\text { equivalents, respectively. } p \text { values are from primary analysis (hierarchical logistic } \\
\text { models with all three time points included as outcomes and six covariates that } \\
\text { differed at baseline: TESS-NH safety score, QUIS positive social score, } \mathrm{RCS} \text { total } \\
\text { score, global deterioration rating scale for assessment of primary degenerative } \\
\text { dementia score, country of birth and number of comorbid diseases): } \mathrm{p}_{\mathrm{G}} \text { is for main } \\
\text { effect of intervention, } \mathrm{p}_{\mathrm{T}} \text { is for main effect of time (over three time points), and } \mathrm{p}_{\mathrm{GT}} \\
\text { is for the interaction between group and time. Pairwise comparisons from } \\
\text { secondary analysis (hierarchical logistic models with time points after treatment } \\
\text { and at follow-up as outcomes, baseline value of the outcome variable as a } \\
\text { covariate plus the six covariates that differed at baseline) revealed only two } \\
\text { significant contrasts: at follow-up, there were fewer falls with dementia-care } \\
\text { mapping (DCM) than with usual care }\left({ }^{*} \mathrm{p}=0.02\right) \text { and more falls with } \\
\text { person-centred care (PCC) than with usual care ( } \mathrm{t} p=0.03 \text { ). }\end{array}$} \\
\hline $\begin{array}{l}\text { Table 3: Pro } \\
\text { receiving dr }\end{array}$ & f residents $\mathrm{n}$ & or more in & and \\
\hline
\end{tabular}

Outcomes at sites providing person-centred care were more variable than at those providing dementia-care mapping and usual care sites. Structural differences in intervention delivery might have affected the results. All residents at mapping sites, but only one in three at sites providing person-centred care, had care plans devised at

\begin{tabular}{|c|c|c|c|c|c|c|c|c|c|c|}
\hline & $\begin{array}{l}\text { Mean } \\
\text { number of } \\
\text { residents } \\
\text { per site }\end{array}$ & $\begin{array}{l}\text { Change in } \\
\text { CMAI after } \\
\text { intervention }\end{array}$ & $\begin{array}{l}\text { Change in } \\
\text { CMAI at } \\
\text { follow-up }\end{array}$ & $\begin{array}{l}\text { Total CMAI } \\
\text { reduction for } \\
\text { site after } \\
\text { intervention* }\end{array}$ & $\begin{array}{l}\text { Total CMAI } \\
\text { reduction for site } \\
\text { at follow-up* }\end{array}$ & $\begin{array}{l}\text { Incremental cost } \\
\text { of intervention } \\
\text { per site* }\end{array}$ & $\begin{array}{l}\text { Cost per CMAI } \\
\text { point averted } \\
\text { after } \\
\text { intervention* }\end{array}$ & $\begin{array}{l}\text { Cost per } \\
\text { CMAI point } \\
\text { averted at } \\
\text { follow-up* }\end{array}$ & $\begin{array}{l}\text { Cost per CMAI } \\
\text { point averted } \\
\text { vs } \mathrm{PCC} \text { after } \\
\text { intervention }\end{array}$ & $\begin{array}{l}\text { Cost per CMAI point } \\
\text { averted vs PCC at } \\
\text { follow-up }\end{array}$ \\
\hline $\begin{array}{l}\text { Usual } \\
\text { care }\end{array}$ & $16 \cdot 4$ & $+8 \cdot 4$ & $+7 \cdot 4$ &.. &.. &.. &.. &.. &. & .. \\
\hline PCC & $19 \cdot 6$ & $-5 \cdot 8$ & $-10 \cdot 3$ & 281 & 350 & $\$ 2250$ & $\$ 8.01$ & $\$ 6.43$ &.. & .. \\
\hline DCM & $21 \cdot 8$ & $-1 \cdot 0$ & $-2 \cdot 4$ & 205 & 214 & $\$ 10034$ & $\$ 48.95$ & $\$ 46.89$ & $-\$ 102 \cdot 42$ & $-\$ 57 \cdot 24$ \\
\hline
\end{tabular}


the start of the intervention. Mapping procedures provided more detailed direction to person-centred care planning and application for individual residents because the assessment tool pinpoints discrete factors to be addressed and recommended strategies. At sites providing person-centred care, staff had more autonomy in determining specific ways to develop and apply personcentred care plans. In other words, the reduction in agitation might be related to staff personally identifying issues for care, whereas in mapping sites, care planning was informed by the detailed observations made by the people doing the mapping and by their suggestions for improving care delivery. Person-centred care encourages all staff to initiate, become involved in, and take ownership of changes in practice, whereas feedback and suggestions for change in dementia-care mapping are driven by those staff trained in the intervention.

Several explanations are possible for the lack of effect in outcome measures other than agitation. Although severe behavioural and psychiatric-related behaviours, as measured with the neuropsychiatric inventory, improved over time with person-centred care, this did not result in a statistically significant benefit relative to usual care as it did for CMAI. This finding might be because the psychiatric symptoms measured with the neuropsychiatric inventory, such as delusions and hallucinations, are less likely to be affected by psychosocial care approaches than is need-driven dementia-compromised agitation. Furthermore, even if the person-centred care or dementiacare mapping did improve psychiatric symptoms, such improvements would be more difficult for observers to detect than behaviours included in the CMAI. Although both interventions reduced agitation, which is an important factor in quality of life for people with dementia, no improvement in quality of life was recorded for either group. This finding might be because the items included in QUALID, such as enjoyment of eating, touching, and interacting, are more subtle experiences and therefore more difficult to observe and judge than the overtly agitated behaviours recorded in the CMAI. Newer instruments, such as the DEMQOL, might be more apt for future studies of dementia-care residents.

The study has several strengths. The cluster design is suited to small, self-contained dementia units, which are ideal for grouping by site, and it is a feasible and rigorous way to test models of nursing care. We ensured sites reflected the diversity of dementia-care units, were of similar standards (all accredited by the Australian Government Accreditation Standards Agency), and used various validated dementia assessment measures for baseline and outcomes. Participation was stable and attrition low, with 236 (82\%) of an initial 289 completing follow-up. Ratings were done without knowledge of group assignment by use of standardised methods well validated for this population. Those who delivered person-centred care and dementia-care mapping were highly experienced in both interventions and adhered to protocols developed by Bradford University. Finally, previous investigators have commented on the difficulties that recalcitrant management and staff resistance pose to successful research in residential care. ${ }^{6,15}$ Our success in completing the trial and achieving positive outcomes with both interventions was underpinned by cooperative relations with management who enabled sufficient staff involvement in the process.

Limitations of our study include the assignment of single recorders for each intervention. However, any recorder bias is likely to have been consistent across all assessments, and baseline records allowed us to adjust for this in our analysis of repeated measures. Second, blinding of randomised controlled trials of psychosocial interventions is always a challenge. We made every effort to ensure that recorders were unaware of assignment: nursing-home staff signed agreements not to mention the intervention to the research assistants, no questionnaires included intervention information, and the research assistants stated when questioned throughout the study that they were unaware of the sites to which they were allocated. Because site staff were trained in a particular intervention and were a source of outcome measurement, they could not be blinded. However, our use of standard validated questionnaires and structured interviews, as well as observations by research assistants, mitigated this effect. We do not know whether variability in provision of information by nurses introduced bias in outcome measurements. Third, we cannot guarantee that the participating nursing homes were representative of Australian residential facilities for people requiring the highest level of care, even though they were representative in terms of resident age, sex, and level of dependency. Although management and staff at those centres that participated might have been more enthusiastic and open to accepting training than others, we would expect this also to hold for the usual care sites, because they were randomly allocated after initial screening occurred. Fourth, the three experimental groups were imbalanced at baseline on the outcomes measures; one of the disadvantages of the cluster-randomised approach. However, this was the only feasible study design, and our statistical modelling took this into account. Finally, we have only limited data, including the QUIS observations and care manager reports of what staff actually did as a result of the intervention to improve resident care.

Agitation is distressing to people with dementia and those in contact with them, incurring costs in increased staff time and potential for falls and use of restraints. An important implication of this study is that consideration should be given to the introduction of person-centred approaches as standard practice in residential facilities for elderly people or those with dementia, not just to reduce distress in residents, but to enable staff to identify and meet residents' unmet psychosocial needs. Personcentred care can be taught quickly and might have effects lasting for several months. Although the benefits of 
dementia-care mapping were also clear, the intensive and time-consuming training might make it impractical for most residential facilities. If our results are replicated, the modest decrease in cost per unit reduction in agitation for person-centred care warrants its systematic introduction into residential aged care services.

\section{Contributors}

LC led study design, implementation of interventions, and staff training, supervised all project staff, wrote research reviews and grant application, took major responsibility for preparation of the Article, and contributed to subsequent revisions. MTK contributed to research design and selection of outcome measures, made sample-size calculations and did site randomisation, devised and supervised statistical analysis and presentation of results, and contributed to writing and editing of the Article. Y-HJ contributed to study design and implementation of dementia-care mapping, supervision of research assistants for data collection and management, development of databases, identification of relevant research, writing the methods section of the Article, revising drafts of article, and responding to the reviewers' comments. HB contributed to study design, monitoring of study conduct, consultation on statistical analyses, writing the Article, and multiple revisions. JS-P was involved in study design, took responsibility for education, training, and supervision for person-centred care, assisted with data analyses, prepared the description of person-centred care for the Article, assisted with writing of each draft, and made a substantial contribution to the discussion section. RN did the economic assessment and assisted with writing of each draft. MH designed the data collection for the economic analysis, supervised the data analysis for economic assessment, and contributed to preparation of Article and all revisions. GL contributed to data preparation, did statistical analyses, prepared figures and tables, contributed to development of the Article, writing, and editing.

\section{Conflicts of interest}

We have no conflicts of interest.

\section{Acknowledgments}

This study was funded by a grant from the Australian Health Ministers' Advisory Council. We thank Patsy Kenny for her assistance with the random coefficient modelling of the resident outcomes data; participating residents with dementia, nurses, care staff, and managers from the 15 study sites; and members of the management committee for their cooperation and participation.

References

1 Kitwood T. The experience of dementia. Aging Ment Health 1997; 1: 13-22.

2 Access Economics. Dementia in the Asia pacific region: the epidemic is here. http://www.alz.co.uk/research/files/apreport.pdf (accessed Nov 25, 2007).

3 Wiener J. Quality assurance for long-term care: the experiences of England, Australia, Germany and Japan. AARP: Washington, 2007

4 McLucas J. Matters of public importance: Belvedere Park Nursing Home, Senate Hansard, Canberra: Parliament of Australia. http://www.agedcarecrisis.com (accessed Sept 14, 2007).

5 Australian Government, Department of Health and Ageing. Aged care in Australia. 2006. www.health.gov.au/internet/main/ publishing/nsf/Content/3AD1796A625CECA256F19000F1FAA/ \$File/AgedCareinAustralia (accessed Dec 1, 2006).

6 Brooker DJ, Wooley RJ, Lee D. Enriching opportunities for people living with dementia in nursing homes: an evaluation of a multi-level activity-based model of care. Aging Ment Health 2007; 11: 361-70.

7 Brooker $\mathrm{D}$. What is person-centred care in dementia. Rev Clin Gerontol 2004; 13: 215-22.

8 Loveday B, Kitwood T. Improving dementia care: resource for training and professional development. UK: University of Bradford, 1998.

9 Edvardsson D, Winblad B, Sandman PO. Person-centred care of people with severe Alzheimer's disease: current status and ways forward. Lancet Neurol 2008; 7: 362-67.
10 Cohen-Mansfield J, Libin A, Marx M. Non-pharmacological treatment of agitation: a controlled trial of systematic individualised intervention. J Gerontol A Biol Sci Med Sci 2007; 62: 908-16.

11 Sloane PD, Hoeffer B, Mitchell CM, et al. Effect of person-centered showering and the towel bath on bathing-associated aggression, agitation, and discomfort in nursing home residents with dementia: a randomized, controlled trial. J Am Geriatr Soc 2004; 52: 1795-804.

12 Fossey J, Ballard C, Juszczak E, et al. Effect of enhanced psychosocial care on antipsychotic use in nursing home residents with severe dementia: cluster randomized trial. BMJ 2006; 332: 756-61.

13 Brooker D. Dementia care mapping: a review of the research literature. Gerontologist 2005; 45: 11-18.

14 Brooker D, Foster N, Banner A, Payne M, Jackson L. The efficacy of dementia care mapping as an audit tool: report of a 3-year British NHS evaluation. Aging Ment Health 1998; 2: 60-70.

15 Brooker D, Surr C. Dementia care mapping (DCM): initial validation of DCM 8 in UK field trials. Int J Geriatr Psychiatry 2006; 21: 1018-25.

16 Sloane PD, Brooker D, Cohen L, et al. Dementia care mapping as a research tool. Int J Geriatr Psychiatry 2007; 22: 580-89.

17 Beavis D, Simpson S, Graham I. A literature review of dementia care mapping: methodological consideration and efficacy. J Psychiatr Ment Health Nurs 2002; 9: 725-36.

18 Sloane PD, Mitchell CM, Weisman G, et al. The therapeutic environment screening survey for nursing homes (TESS-NH): an observational instrument for assessing the physical environment of institutional settings for persons with dementia. J Gerontol B Psychol Sci Soc Sci 2002; 57: S69-78.

19 Commonwealth of Australia. The resident classification scale-the residential care manual. Canberra: AGPS, 1997.

20 SAS Institute Inc. SAS/STAT user's guide, version 8. Cary: SAS Institute Inc, 1999.

21 Chenoweth L, Jeon Y-H. Determining the efficacy of dementia care mapping as an outcome measure and a process for change: a pilot study. Aging Ment Health 2007; 11: 237-45.

22 Bradford Dementia Group. Dementia care manual, 7th edn. Bradford: University of Bradford, 1997.

23 Reisberg B, Ferris SH, de Leon MJ, Crook T. The global deterioration scale for assessment of primary degenerative dementia. Am J Psychiatry 1982; 139: 1136-39.

24 Dean R, Proudfoot R, Lindesay J. Quality of interactions schedule (QUIS). Int J Geriatr Psychiatry 1993; 8: 819-26.

25 Cohen-Mansfield J. Measurement of inappropriate behaviour associated with dementia. J Gerontol Nurs 1999; 25: 42-51.

26 Cummings JL, Mega M, Gray K, Rosenberg-Thompson S, Carusi DA, Gornbein J. The neuropsychiatric inventory: comprehensive assessment of psychopathology in dementia. Neurology 1994; 44: 2308-14.

27 Weiner M, Martin-Cook K, Saine K, Foster B, Fontaine C. The quality of life in late-stage dementia (QUALID) scale. J Am Med Disord Assoc 2000; 1: 114-16.

28 Woods SW. Chlorpromazine equivalent doses for the newer atypical antipsychotics. J Clin Psychiatry 2003; 64: 663-67.

29 Norman R, Haas M, Chenoweth L, et al. Dementia care mapping and patient-centred care in Australian residential homes: an economic evaluation of the care study. Sydney: Centre for Health Economics Research and Evaluation, 2008.

30 Commonwealth Department of Health and Ageing. Manual of resource items and their associated costs for use in major submissions to the Pharmaceutical Benefits Advisory Committee involving economic analyses. Canberra: Commonwealth of Australia, 2002.

31 Murray DM. Design and analysis of group-randomised trials. Oxford: Oxford University Press, 1998.

32 SAS Institute Inc. The Glimmix procedure. Cary: SAS Institute, 2006.

33 Ayalon L, Gum AM, Feliciano L, Areán PA. Effectiveness of non-pharmacological interventions for the management of neuropsychiatric symptoms in patients with dementia: a systematic review. Arch Intern Med 2006; 166: 2182-88. 